\title{
Impact Factor 2.0: Applying Social Network Analysis to Scientific Impact Assessment
}

\author{
Christian Pieter Hoffmann \\ University of St. Gallen \\ christian.hoffmann@unisg.ch
}

\author{
Christoph Lutz \\ University of St. Gallen \\ christoph.lutz@unisg.ch
}

\author{
Miriam Meckel \\ University of St. Gallen \\ miriam.meckel@unisg.ch
}

\begin{abstract}
Social media are becoming increasingly popular in scientific communication. A range of platforms are geared specifically towards the academic community. Proponents of the altmetrics approach point out that these new media allow for new avenues of scientific impact assessment. Traditional impact measures based on bibliographic analysis have long been criticized for overlooking the relational dynamic of scientific impact. We therefore propose an application of social network analysis to researchers' interactions on an academic social networking site in order to generate new metrics of scientific impact. Based on a case study conducted among a sample of Swiss management scholars, we analyze how these new relational metrics relate to traditional, offline impact indicators as well as online communication activity and publication resonance. We conclude that a relational approach based on social network analysis may add richness and differentiation to scientific impact assessment.
\end{abstract}

\section{Introduction}

Recently, educational publisher Elsevier took over the online reference management service Mendeley for a sum speculated to be between 69 and 100 million US Dollar. Only a few weeks later, Bill Gates, along with other investors, invested 35 million US Dollar in ResearchGate, a leading social network site (SNS) for scientists. These developments document a significant interest in social media solutions in the field of scientific communication. Aside from social network and reference management sites, other social media tools have found avid use within the scientific community. Prominent researchers, such as Fields Medal winning mathematician Terence $\mathrm{Tao}^{1}$ or media scientist danah boyd ${ }^{2}$, use blogs to share their thoughts, publish ad-hoc research, or collect feedback from the scientific community. Twitter has become a powerful communication tool for purposes as diverse as

\footnotetext{
${ }^{1} \mathrm{http}: / /$ terrytao.wordpress.com

${ }^{2}$ http://www.zephoria.org/thoughts
}

networking, information gathering, knowledge dissemination, and conference chatter [34:50-71].

Despite anecdotal evidence on the increasing importance of social media in scientific communication, little is known about researchers' adoption of social media: Do scientists use social media to promote their output and enhance their standing within the community, i.e., to generate impact? Is the number of online contacts or followers related to a scholars' standing within the community? How do offline measures of scientific impact, such as academic position, seniority, or number of citations, relate to new online measures of impact?

This paper will contribute to the state of knowledge on social media use in academia by focusing on the latter question: We collected use data on the academic networking platform ResearchGate generated by members of the business department of a Swiss university in order to explore if and how scientific impact can be assessed by applying a network analysis approach to social media data. We test the relationship between relational metrics and various more established measures of impact. Our analysis thereby also contributes to current debate on impact assessment based on online data ("altmetrics") by focusing on a relational, personal networking perspective [39].

So far, network centrality measures based on social network analysis of online SNS have not been considered in the context of impact assessment. Our results, while based on a small, explorative study, suggest that such measures do relate to established impact metrics and therefore might be helpful, at least in complementing existing forms of impact assessment.

\section{Theoretical background}

\subsection{Social Media Use in Academia}

Social media are becoming more and more popular in scientific communication [4,41]. They provide a channel for the speedy dissemination of research results and the interaction with both peers and lay audiences. The open access philosophy has further 
strengthened the appeal of social media as a tool for academic communication [33,35]. Increasingly, institutional imperatives, such as pressure by funding agencies and grant committees, drive researchers to display the importance of their work online ${ }^{3}$.

Buzzwords such as open access, open data, science 2.0, cyberscience, or networked science [34,35] indicate an "opening up" of the research process due to new communication technology, increasing collaboration and the integration of diverse cooperation partners or audiences. Today, the co-authorship of scientific papers is much easier and more common than 20 years ago due to the affordances of new communication technologies [23]. Social media are especially effective in establishing and managing personal connections. Blogs, Twitter, and academic social network sites enable more flexible forms of both cooperation and publication than traditional outlets, such as conferences and journals [15,19,38,46].

Considering the potential impact of social media on scientific communication practices, only limited research has addressed their adoption and effects in the scientific community. To date, most findings are exploratory and descriptive: Procter et al. [42] found that web 2.0 adoption among scientists is influenced by demographic characteristics, such as age (the younger the more frequent social media use), gender (males being more frequent users), but also by position, and discipline. As for the last factor, "computer scientists and mathematicians" exhibit the highest percentage of frequent use (26 percent), whereas biologists show the least enthusiasm ( 3 percent). The authors also showed that collaboration practices, support, skills, and attitudes play an important part in shaping scholars' adoption of web 2.0 applications.

More recently, Gruzd and Goertzen [24] conducted an online survey among the members of three professional social science organizations. Based on Uses and Gratifications Theory, they identified key motives for social media use among academics, such as "keeping up to date with topics", "following other researchers' work" and "discovering new ideas or publications". Overall, information uses are more prevalent than communication and networking. The survey also revealed that, currently, non-academic SNS and blogs are the most popular applications for frequent use, followed by online document management services. When it comes to future use intentions, though, academics are most prone to adopt presentation sharing sites, bibliographic management sites (e.g. Mendeley), and academic social network sites (e.g. Academia.edu or ResearchGate).

\footnotetext{
${ }^{3}$ http://www.nsf.gov/social/policies.jsp
}

Given their comparatively recent establishment, it does not surprise that little research has investigated academic SNS, their structure, mechanisms, and use. However, considering their rising prominence, we deem them worthy of further analysis. In a conventional definition, social network sites (SNS) were defined as: "web-based services that allow individuals to (1) construct a public or semi-public profile within a bounded system, (2) articulate a list of other users with whom they share a connection, and (3) view and traverse their list of connections and those made by others within the system" [13]. In this sense, sites like Academia.edu, ResearchGate, and Mendely are classical SNS as they fulfill all of these criteria. They are geared towards a scientific audience, however, and include additional functions, such as uploading and sharing articles, endorsing colleagues (ResearchGate), or finding literature that is similar to the one already used (Mendeley).

\subsection{Measuring Scientific Impact}

Today, scientific impact is mostly measured by bibliographic metrics [cf. 5 for an overview]. Citations and publications in peer-reviewed journals are the key indicators of academic merit. While on the journal level, the most prominent measure is the Impact Factor [21], the h-Index has emerged as a popular metric focusing on the individual researcher [27]. Both measures have been criticized on various grounds:

While bibliographic metrics do indicate the ability to pass peer-review and a degree of peer attention, journal publications are only one indicator of scientific impact [37]. Impact, understood as a researcher's esteem and influence within the scientific community, relates to the dynamics of scientific communication. As the tools of scientific communication evolve, new opportunities to assess impact arise - and traditional tools, such as journal-based bibliometrics, become more contested [41].

Critics point out that impact measures based on journal publications and corresponding databases make disciplines where other forms of publication are common difficult to evaluate. "Alternative" forms of publication that all too often fly under the radar of common metrics include books (liberal arts, linguistics, social sciences), reports, presentations, or conference proceedings (computer science). New possibilities of sharing output, such as data sets or code, are not reflected in traditional measures, either [45]. Instead, they foster a culture of citation cartels and journal selfcitations, while neglecting the context of citations, i.e. why and how certain articles were cited [37].

There are two theoretical angles from which traditional bibliographical impact measures have been 
scrutinized. First, they are criticized for undervaluing informal aspects of academic influence, such as commitment to the community, embeddedness in research groups, or outreach beyond the scientific community [37]. In other words, social networks have been undervalued by traditional impact evaluation.

Studies employing a relational perspective and relying on social network analysis (SNA) are well established in the social sciences [20]. They analyze forms of relationships between individuals, in some cases focusing on the academic community [54]. Here, possible forms of relations range from acquaintances and co-memberships in professional organizations, to virtual communication exchange via e-mail or social media, to co-authorship, and author-intercitation [32].

The concept of invisible colleges captures important aspects of scientific communities in terms of networking and social relations [14]. "Members [of invisible colleges] convene meetings; talk to and write other members; battle over claims and theories; exchange drafts, preprints, and reprints of their articles for critical scrutiny; and routinely enter into various forms of collaboration, including co-authorships" [54:275]. Within invisible colleges, core members - or influentials - can be detected with SNA, using centrality measures. Therefore, applying a relational perspective to scientific impact assessment may provide a promising avenue of evaluation $[16,30,55]$.

A second theoretical criticism of bibliographic measures is based on capital theories. Bourdieu famously discussed traditional criteria of academic influence and power [11]. His field-theoretical work has shaped many social scientists' understanding of the academic world. In his categorization of capital forms in academia, Bourdieu distinguished more external and economic forms from more internal ones: He described institutional power at the university level (e.g. being a dean) as an indicator of external capital, and peer reputation (managing a research team, being on an editorial board etc.) as an indicator of internal capital.

While traditional bibliographical measures of impact do include a seniority component, as they need time to accumulate, they are slow to adapt to changes in social status or relational capital, just as they are slow in revealing current research trends $[8,19]$.

Traditional metrics have advantages, too: they allow comparability, are conventional and widely understood, and they are relatively easy to compute [5]. Still, a consensus emerges that scientific impact cannot be measured by citation analysis alone [9]. Instead, measures should be context-specific, since the social, symbolic and harder-to-grasp components of "impact" may have a strong effect. Bourdieu reminds us that the realm of statements (i.e., publications) is a mere expression of the actual social space $[10,12]$. It is the distribution of field-specific capital that determines how and what scholars are able to achieve [11].

In summary, we identify three approaches to gauging the impact of a researcher: a citation-based, a network-based, and a capital-based approach. The variety of these approaches documents the complexity of the issue at hand $[5,19,39]$. As the next section will show, the emergence of the Internet as a space for scientific communication facilitates, in some cases enables the analysis of scientific impact considering all three approaches discussed above.

\subsection{New Approaches: Altmetrics}

New opportunities to assess scientific impact emerge as scholarly communication evolves. Currently, alternative metrics of scientific impact based on online media are being developed and tested. Still in its infancy, the altmetrics approach constitutes a promising field of inquiry. This is especially true because social media provide a wealth of data, and thereby increase the transparency of scientific communities [39,41]. By making connections visible and by analyzing social media data, social scientists gain new insights into the structure and dynamics of academic work.

The Altmetrics Manifesto compiles a compact summary of the goals and scope of the altmetrics approach [40]. Impact metrics are described as multifaceted constructs, comprised of the following four pillars: usage, peer-review, citations, altmetrics.

Altmetrics are not meant to replace traditional, bibliometric measures of academic influence. They are suggested to complement and question them: altmetrics service ImpactStory, for example, collects data from social media outlets, ranging from general purpose applications, like Twitter, Wikipedia, and Facebook, to specific academic solutions, such as Mendeley and PLoS. It then creates a report including statistics of all the platforms considered (likes, retweets, downloads, citations). The service demonstrates the multi-faceted nature of scientific communication, collaboration and outreach. Webometrics and altmetrics can be applied on the level of a journal $[47,49]$, a single article $[31,50]$ or an individual researcher [1]. In their roadmap, the authors of the Altmetrics Manifesto call for research that compares altmetrics with other measures of academic influence: "Researchers must ask if altmetrics really reflect impact, or just empty buzz. Work should correlate between altmetrics and existing measures, predict citations from altmetrics, and compare altmetrics with expert evaluation" [40].

Some social media services have reacted to the emergence of altmetrics by providing their own online metrics of impact. ResearchGate, for example, 
calculates a "ResearchGate Score" for each of its members. The score is comprised of four indicators: number of publications, questions asked in the community, answers given in the community, and number of followers. To date, the company has not released the precise formula underlying its impact score. Given its composition, it is geared to encourage platform engagement among users.

\subsection{Research Framework}

We hypothesize that social media allow for new metrics of scientific impact, particularly focusing on the relational dimension of communication and influence. SNS allow users to articulate and manage their personal networks [13]. Network analysis, in turn, reveals a member's centrality within a network, which can be (and commonly is) interpreted as a measure of prominence [51]. Structural analyses based on social media networks may therefore be able to contribute to the development of scientific impact assessment via new media. We suggest a researcher's centrality within online social networks as a measure of scientific impact. To estimate the quality of such measures, we will test their relationship to established offline as well as more current online measures of impact based on a small-scale exploratory study conducted in Switzerland.

We will consider the following indicators to analyze the relationships between online and offline measures of scientific impact,:

1. Seniority: As described by Bourdieu [11], academia tends to institutionalize reputation and influence (social capital) in the form of prizes and awards, formal positions, rankings, or membership in editorial boards. We will therefore consider researchers' seniority.

2. Publication impact: This traditional, bibliometric measure focuses on a researcher's output. Traditional success metrics include journal impact factors or the $h$ index. Increasingly, the impact of publications can also be gauged online, e.g. in the form of likes, downloads or shares. We will therefore also consider the online resonance of publications.

3. Network Centrality: A measure derived from a relational analysis, it describes how a researcher is connected to other members of the scientific community - and thereby indicates her prominence, standing, and influence. In addition to mere activity, this measure analyses the relationships built by a researcher.

As a control variable, we will also consider Online Activity. While not an impact measure itself, online activity is a prerequisite of online measures of impact and a key foundation of the altmetrics approach. High levels of online communication activity may impact a researcher's reputation and standing within the community, i.e., result in scientific impact.

\section{Methodology}

\subsection{Data and Methods}

55 faculty members of a Swiss public university's school of management participated in the study. By signing a declaration of consent, they agreed to grant the authors access to their interaction data generated on the academic SNS ResearchGate over the course of half a year, from September 2012 until February 2013. The data includes information such as follower relationships, likes, shares or comments. We received the dataset from ResearchGate by mid-February 2013, and subsequently analyzed the participants' network structure using SNA [7,18,44,51].

Study participants cover a wide range of academic positions as well as twelve different, independent organizations (institutes) within the school. The institutes cover various fields of research, such as media and communications, technology management, pedagogy, IS or marketing. They operate as independent profit centers. 50 percent of participants are doctoral students/research associates, 30 percent are post-docs and junior/assistant professors, and 20 percent are full professors. As for gender, 20 percent are female and 80 percent male (representative of the faculty's gender composition).

We used UCINET/Netdraw [6] and Gephi [3] to analyze and visualize the directed network data. To assess the relationships between the different indicators of academic impact, we computed pairwise correlations in STATA (v. 9).

\subsection{Platform}

According to its own reports, ResearchGate has over 3 million members as of August 2013. A large part of the membership base stems from medicine and biology. In general, natural sciences figure more prominently on the platform than social sciences and humanities. On ResearchGate, users can establish a personal profile with academic information, share publications and datasets, engage in discussions, up/downvote publications and discussion topics, write messages, search for and monitor peers as well as their own impact via the ResearchGate score [22]. The platform shares many functions with services such as Facebook and LinkedIn, but is geared towards a scientific audience. 


\subsection{Measures}

We operationalized the Seniority criterion by grouping the sample into five categories according to academic position. We distinguished between undergraduate students $(0)$, doctoral students (1), postdocs and project managers without professorship (2), junior/assistant professors (3), and full professors (4).

We used two measures to gauge Publication impact: We employ the term Publication success to denote a traditional "offline" measure of publication impact, the h-Index [27]. The h-Index is a widely used measure for publication success and seems to perform relatively well in terms of robustness and prediction power [28]. Data was collected from two databases: ISI Web of Knowledge and Google Scholar. For Google Scholar we computed the h-Index with Harzing's "Publish or Perish" software [26], and for ISI Web of Knowledge we used the built-in option of giving out the h-Index for individual researchers.

In order to account for the altmetrics approach to impact assessment [40], we analyze a second measure termed Publication resonance. This measure addresses the resonance of publications on ResearchGate and is based on an index comprised of four indicators: publication views, downloads, number of upvoted publications, and number of bookmarked publications. The indicators were weighted according to the required involvement and the respective importance. We normalized this index so that the maximum value is 1 and the minimum value 0 .

Finally, Network Centrality was measured with four centrality measures: (in)degree centrality, Freeman's closeness/farness centrality, betweenness centrality and eigenvector centrality as expressed by Bonacich power [25]. For indegree centrality we considered both the core network of researchers who signed the consent form $(\mathrm{N}=55$; thus the maximum possible value is 54 , and the minimum 0 ) and overall followers (the maximum is the number of ResearchGate users - 1, i. e. roughly 3 million, and the minimum again 0 ).

Centrality is an essential concept in SNA and captures a person's prominence within a network. Different centrality measures relate to different conceptual meanings: indegree, for example, is a person's "visibility" and measures "where the action is" [51:179], whereas closeness centrality captures how quickly someone in a network reaches others or can be reached (reachability). High indegree centrality on ResearchGate indicates prominence and high visibility of activity or output. By contrast, high scores on closeness centrality indicate that a user can easily connect with other members, e.g. through referrals from personal contacts. Similarly, betweenness centrality - which measures bridging, control or gatekeeping - is an indicator of cluster connection. Hence, high betweenness scores might point to interdisciplinarity and variety in a member's network. Finally, eigenvector weighs the importance of someone's connections in the network. Being connected to many people that are themselves connected to many others would result in a high eigenvector centrality score. In our case, eigenvector could be interpreted as a measure of resonance or impactful communication.

The control variable Online Activity was measured with a normalized activity index, summing up the following four ResearchGate metrics: number of uploaded fulltext publications, number of followings, number of questions, and number of answers given. These four dimensions largely cover the communication activities facilitated by the platform. We deemed these measures preferable to self-reported data which may be subject to reply biases [17]. Logfiles were not available to the authors but could also provide reliable measures of online activity.

\section{Results and Discussion}

\subsection{Descriptive Data Analysis}

Figure 1 shows the structure of the follower network on ResearchGate for our sample $(\mathrm{N}=45 ; 10$ isolates not in the graph; coloring $=$ indegree: the higher the indegree, the lighter the node).

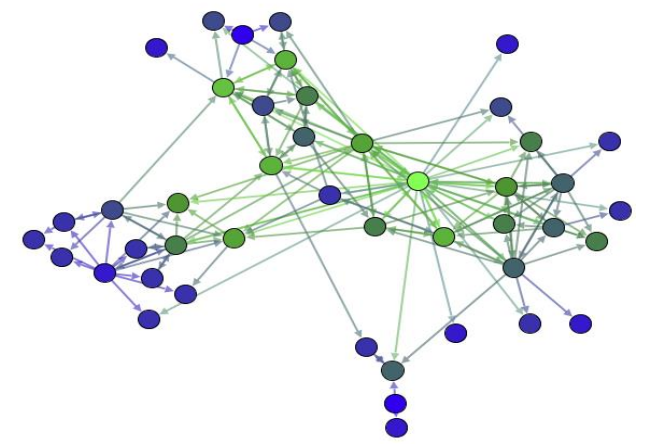

Figure 1. Network structure of the sample

Thus, it shows who follows whom on the platform. Table 1 provides basic network statistics of this follower network. With a low average path length and a high clustering coefficient, the network reveals typical attributes of small world networks [52]. The low value of the E-I Index points to high homophily. When study participants use ResearchGate for networking, they tend to follow institute peers they already know rather than establishing new contacts. This fact is compounded by a low density and a 
relatively high number of isolates. Homophily in our sample goes hand in hand with inactivity as the activity data on the platform shows: only two of the researchers have replied to questions/discussion threads.

Table 1. Basic network metrics of the sample

\begin{tabular}{|l|l|}
\hline Measure & Value \\
\hline $\begin{array}{l}\text { Average Degree Sample } \\
\text { Average and Median } \\
\text { Indegree Overall } \\
\begin{array}{l}\text { Average and Median } \\
\text { Outdegree Overall }\end{array}\end{array}$ & $\begin{array}{l}9.04 \\
9.98 \text { / Median: } 5\end{array}$ \\
\hline Density & 7.74 / Median: 1 \\
\hline Clustering Coefficient & 0.06 \\
\hline E-I Index fore Institute & 0.48 \\
Membership & -0.08 (expected: \\
\hline Average Distance & $0.69)$ \\
\hline Diameter & 2.43 \\
\hline Isolates & 6 \\
\hline
\end{tabular}

In our sample, assistant professors occupy the most central positions, not senior faculty (Figure 2; black = $\mathrm{PhD} ;$ blue $=$ post-doc $;$ red $=$ full professors; white $=$ assistant professors; $\mathrm{N}=45 ; 10$ isolates omitted).

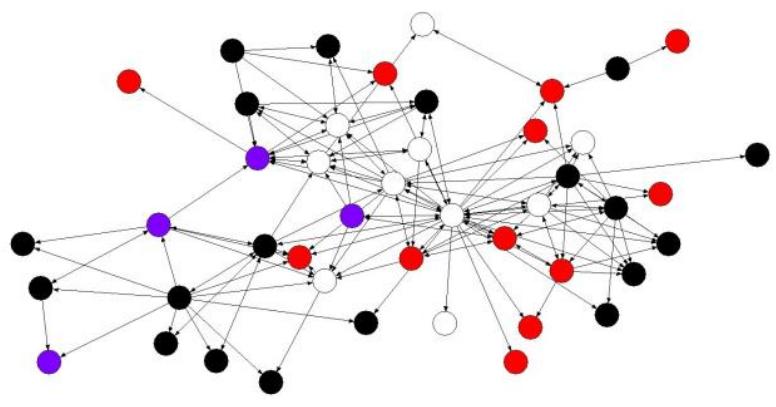

Figure 2. Network coloring according to academic position

\subsection{Correlation Analysis}

Table 2 shows the results of the correlation analysis. First, Online activity is strongly correlated with all measures of centrality but not with Publication impact or Seniority. This implies that network-based measures are related to network-based communication activity, which in turn does not necessarily affect traditional or offline measures of impact.

Second, while both Publication impact measures strongly correlate, it is indeed important to differentiate publication impact by online or offline measures. The traditional offline measure, Publication success, is related to Seniority and the overall indegree centrality. This could be interpreted as more senior academics enjoying higher publication success and therefore more prominence within the overall online network.

Table 2. Correlation between indicators of academic impact

\begin{tabular}{|c|c|c|c|c|}
\hline & 2 & 3 & 4 & 5 \\
\hline Activity (1) & $.64^{* \star *}$ & $.54^{* \star *}$ & $35^{\star \star \star}$ & $.59^{\star \star *}$ \\
\hline \multirow[t]{2}{*}{$\begin{array}{l}\text { Centrality } \\
\text { OI (2) } \\
\text { SI (3) } \\
\text { C (4) }\end{array}$} & & $.79^{\star \star \star}$ & $\begin{array}{l}.56^{\star \star \star} \\
.71^{\star \star \star}\end{array}$ & $\begin{array}{l}.44^{* * *} \\
.61^{\star * *} \\
\text { n. s. }\end{array}$ \\
\hline & 6 & 7 & 8 & 9 \\
\hline Activity (1) & $.55^{\star \star \star}$ & n. s. & n. s. & n. s. \\
\hline $\begin{array}{l}\text { Centrality } \\
\text { OI (2) } \\
\text { SI (3) } \\
\text { C (4) } \\
\text { B (5) } \\
\text { EV (6) }\end{array}$ & $\begin{array}{l}.74^{\star \star \star} \\
.94^{\star \star \star} \\
.71^{\star \star \star} \\
.49^{\star \star \star}\end{array}$ & $\begin{array}{l}.48^{\star * \star} \\
.30^{\star} \\
.39^{\star \star} \\
\text { n. S. } \\
.33^{\star}\end{array}$ & $\begin{array}{l}.51^{* * *} \\
\text { n. s. } \\
\text { n. s. } \\
\text { n. s. } \\
\text { n.s. }\end{array}$ & $\begin{array}{l}.53^{\star \star \star} \\
.36^{\star \star \star} \\
.44^{\star \star \star} \\
\text { n. s. } \\
.42^{\star \star *}\end{array}$ \\
\hline $\begin{array}{l}\text { PR (7) } \\
\text { PS (8) }\end{array}$ & & & $.65^{\star \star *}$ & $\begin{array}{l}.79^{\star \star \star} \\
.54^{\star \star \star}\end{array}$ \\
\hline \multicolumn{5}{|c|}{$\begin{array}{l}{ }^{*} p<0.05{ }^{* *} p<0.01 \quad{ }^{* * *} p<0.001 \quad(N=55) \\
\text { Ol=Overall Indegree (Number of followers across } \\
\text { sample); SI=Sample Indegree (Number of followers } \\
\text { within sample); C=Closeness Centrality; } \\
B=\text { Betweenness Centrality; EV=Eigenvector Centrality; } \\
\text { PR=Publication Resonance; PS=Publication Success } \\
\text { (WOS h-index); } 9=\text { Seniority }\end{array}$} \\
\hline
\end{tabular}

The online measure, Publication resonance, in turn, also correlates with sample indegree, closeness and eigenvector centrality. Therefore, it appears that network-specific dynamics affect the centrality of researchers as well as their publication impact within the online community. Platform-based communication activities do not influence publication impact.

Table 3. Correlation between different forms of academic impact and activity

\begin{tabular}{|l|c|c|c|}
\hline & A & N & P \\
\hline $\mathbf{N}$ & $\checkmark$ & & \\
\hline $\mathbf{P}$ & $\mathrm{X}$ & $\checkmark / \mathrm{X}$ & \\
\hline $\mathbf{S}$ & $\mathrm{X}$ & $\checkmark$ & $\checkmark$ \\
\hline
\end{tabular}

$\checkmark=$ Correlation; $X=$ No Correlation; $A=$ Online Activity; $N=$ Network Centrality; $P=$ Publication Impact; $S=$ Seniority

Third, Seniority is highly correlated with all centrality measures except for betweenness centrality. Apparently, offline social capital does transfer to the online world. Table 3 shows a simplified summary of the results of our correlation analysis. 


\section{Conclusion}

\subsection{Summary and Implications}

A range of institutions struggle to reliably assess the impact of researchers within the scientific community - among them universities trying to select and incentivize high-impact faculty members. Scientific impact can be understood as a researcher's standing within the scientific community. While difficult to conceptualize and measure, this impact is commonly based on successful communication. As peer-reviewed journals constitute a major outlet of scientific communication, impact assessment has focused on bibliographic metrics estimating the impact of journals or single contributions [21,27]. As new tools of scientific communications emerge, new metrics of impact assessment are being proposed [40].

Our study addresses criticism aimed at traditional measures of impact assessment, specifically their undervaluing relational aspects of scientific impact and social capital formation [37]. While a range of studies indicate that social networks are crucial in driving research disciplines and creating social capital for individual members $[16,30,55]$, bibliometrics do not take account of these dynamics. As SNS facilitate the analysis of personal networks based on online data, we hypothesize that measures of network centrality derived from academic SNS may provide valuable insights to impact assessment.

Based on a small-scale, explorative study among members of a Swiss university department using academic SNS ResearchGate, we compute centrality measures and analyze their relationship to traditional measures of impact assessment. We find that study participants use the academic SNS more as a Facebook-like networking tool than a Twitter-like communication tool $[2,29,43]$. In general, participants do not follow a large selection of their peers. Rather they primarily interact within their offline community, such as institute colleagues. Results indicate large institutional homophily. Thereby, the SNS largely reaffirms rather than extends established communities [16].

We also find that junior and upcoming researchers occupy the most central positions within the analyzed social network. This may be due to more active communication within the online community, as seniority clearly does not correspond with higher online activity in our case.

Furthermore, findings indicate that relational measures derived from ResearchGate are in fact related to more traditional measures of scientific impact. However, they also exhibit some platform-specific dynamics: Senior researchers exhibit significant prominence within the overall network as well as within the sample. Interestingly, while seniority does seem to translate into prominence (as measured by indegree centrality) and influence (as measured by eigenvector centrality), the same does not hold for a bridging positions within the network (as measured by betweenness centrality). Interpreting centrality measures in online networks requires the consideration of platform-specific dynamics, though. As online, connections can be established with a simple click of the mouse, they may not require much involvement. Online connections also do not necessarily require much maintenance. At the same time, considering different centrality measures may be worthwhile as they denote different forms of prominence. High betweenness scores, for example, may indicate outreach beyond established research institutions or clusters (or at least interdisciplinary interest and connectedness) - a form of social capital that is not mirrored by bibliometric criteria.

We find that, in our sample, junior faculty are more active within the online community ${ }^{4}$ and hold the most central positions within the network. This could signify that junior faculty members, striving to establish themselves, more actively try to generate social capital - which might translate into impact further down the road $[36,48,53]$.

At the same time, we find that online communication activity, while related to network centrality, does not correlate with any of the more established impact measures, including the online resonance of publications. Still, we cannot rule out indirect effects, as communication-driven network centrality could translate into impact at a later point.

As to publication impact, we find support for the altmetrics approach in that online publication resonance is highly correlated with seniority, even more so than the traditional offline metric (h-index). Since seniority highly correlates with prominence within the overall network (measured by overall indegree), we find that publication success also interacts with this form of relational capital.

In addition to indegree, online publication resonance also correlates with closeness and eigenvector centrality. Wasserman and Faust [51] describe indegree centrality as visibility. In our case, those with high indegree - and also eigenvector scores expose their output to a larger audience. Thus, it does not surprise that they generate more page views and downloads, as captured by publication resonance. As for closeness, the measure captures reachability.

\footnotetext{
${ }^{4}$ Assistant professors have an average activity index of 0.27 , while full professors score only 0.11 .
} 
Those who are central in terms of closeness are easy to find and connect to - be it directly or indirectly. If we assume that ResearchGate users looking for interesting publications scan their follower and following list as well as their followers' follower and following list (and so on), high closeness centrality would also indicate better accessibility of publications.

In summary, we find indications that a networkbased approach, based on social media data, may contribute to a more diversified system of scientific impact assessment by adding a relational and social capital-based perspective. On the one hand, our findings indicate a number of platform-specific effects: active members of the online community are more central members of their networks, centrality, in turn, is related to publication resonance on the platform. At the same time, we do find that different centrality measures are also related to offline measures of impact, such as seniority and publication success. Since these relationships vary, there is a clear need to further flesh out the specific significance of individual centrality measures.

Given the small and discipline-specific sample employed in this study, we need to be careful when deriving theoretical implications. We found that, in our sample, academic SNS were primarily used for interacting with offline contacts, creating bonding capital between colleagues. These findings may shed additional light on the formation and operation of "invisible colleges" in academia [14]. They may also be dependent on seniority, though, as junior faculty exhibit stronger platform engagement which is related to all forms of network centrality, including betweenness centrality. This may indicate that junior researchers more actively employ SNS in order to extend their personal network beyond established clusters. Our study also contributes to current debate on scientific impact assessment and altmetrics. In our analysis, online publication impact is more strongly related to researcher seniority than offline publication success. Also, online publication impact is significantly related to network centrality, which in turn is strongly related to online communication activity. Relational metrics may therefore serve to shed more light on the dynamics of online and offline publication impact and overall impact in the field.

\subsection{Limitations and Agenda}

Our study is subject to a number of limitations that provide an agenda for future research. First and foremost, the small size and disciplinary focus of the sample allows for only limited inferences beyond the field of the faculty and its research focus. By extending the study to other research domains, future analyses can account for disciplinary idiosyncrasies. Furthermore, studies considering the entire social graph of the SNS platform could tackle a range of open questions and challenges. Such comprehensive (network) data might, however, not be immediately available and subject to confidentiality. To date, ResearchGate has not made its API publicly available.

A second limitation concerns the platform itself and our reliance on it as the unique source of relational data. The platform provides specific functionalities and promotes specific online activities, thereby potentially biasing the results of our analysis. Researchers use a range of different social media tools [24], and future research should consider interaction streams on different platforms. Network data from different academic SNS are necessary to further answer the question of what constitutes and drives academic influence on SNS.

Third, the data at hand reveal only basic attribute characteristics. More detailed descriptions of the involved researchers are necessary to address questions of influence on social media, and especially academic SNS, including, but not limited to, career tracks, web skills, affinity and attitudes, trust, privacy and security concerns, work environment, importance of research partnerships and sharing, etc. Survey data would therefore add valuable context to our findings. Also, qualitative approaches could be applied to generate a more fine-grained picture of how individuals perceive impact within social networks, and how they make sense of the influence landscape.

Finally, future research should look at the use of academic SNS over time. Given the necessary longitudinal data, relational metrics may be able to contribute to a more dynamic perspective on impact assessment: Researchers at various stages in their career might employ online communication tools for different purposes, such as relationship building, promotion, information dissemination. These activities could contribute to different forms of social capital building up to increasingly institutionalized forms of scientific impact.

\section{References}

[1] Aguinis, H., Suárez-gonzález, I., Lannelongue, G., and Joo, H. Scholarly Impact Revisited. Academy of Management 26, 2 (2012), 105-132.

[2] Archambault, A. and Grudin, J. A longitudinal study of facebook, linkedin, \& twitter use. Proceedings of the 2012 ACM annual conference on Human Factors in Computing Systems CHI 12, (2012), 2741. 
[3] Bastian, M., Heymann, S., and Jacomy, M. Gephi : An Open Source Software for Exploring and Manipulating Networks. Artificial Intelligence 2, 2 (2009), 361-362.

[4] Bik, H.M. and Goldstein, M.C. An Introduction to Social Media for Scientists. PLoS Biology 11, 4 (2013), 8.

[5] Bollen, J., Van De Sompel, H., Hagberg, A., and Chute, R. A Principal Component Analysis of 39 Scientific Impact Measures. PLoS ONE 4, 6 (2009), 11.

[6] Borgatti, S.P., Everett, M.G., and Freeman, L.C. Ucinet for Windows: Software for Social Network Analysis. Harvard Analytic Technologies 2006, (2002), SNA Analysis software.

[7] Borgatti, S.P., Mehra, A., Brass, D.J., and Labianca, G. Network analysis in the social sciences. Science 323, 5916 (2009), 892-5.

[8] Bornmann, L. and Daniel, H.-D. What do citation counts measure? A review of studies on citing behavior. Journal of Documentation 64, 1 (2008), 45-80.

[9] Bornmann, L. Is there currently a scientific revolution in scientometrics? Journal of the American Society for Information Science and Technology 91, 3 (2013).

[10] Bourdieu, P. Distinction: A Social Critique of the Judgement of Taste. Harvard University Press, Cambridge, MA, 1984.

[11] Bourdieu, P. Homo Academicus. Stanford University Press, Palo Alto, CA, 1990.

[12] Bourdieu, P. The Rules of Art: Genesis and Structure of the Literary Field. Stanford University Press, Palo Alto, CA, 1996.

[13] Boyd, D. and Ellison, N.B. Social Network Sites: Definition, History, and Scholarship. Journal of ComputerMediated Communication 13, 1 (2007), 210-230.

[14] Crane, D. Invisible Colleges: Diffusion of Knowledge in Scientific Communities. University of Chicago Press, Chicago, 1972.

[15] Desai, T., Shariff, A., Shariff, A., et al. Tweeting the meeting: an in-depth analysis of Twitter activity at Kidney Week 2011. PloS one 7, 7 (2012), e40253.

[16] Dimitrova, D., Gruzd, A., Hayat, Z., et al. NAVEL Gazing: Studying a Networked Scholarly Organization. In K. Evangelos, ed., Advances in Network Analysis and its Applications. Springer, Berlin, 2013, 271-298.
[17] Ellison, N.B., Steinfield, C., and Lampe, C. The Benefits of Facebook "Friends": Social Capital and College Students' Use of Online Social Network Sites. Journal of ComputerMediated Communication 12, 4 (2007), 1143-1168.

[18] Emirbayer, M. Manifesto for a Relational Sociology. American Journal of Sociology 103, 2 (1997), 281-317.

[19] Eysenbach, G. Can Tweets Predict Citations? Metrics of Social Impact Based on Twitter and Correlation with Traditional Metrics of Scientific Impact. Journal of Medical Internet Research 13, 4 (2011), e123.

[20] Freeman, L.C. The Development of Social Network Analysis - A Study in the Sociology of Science. Empirical Press, Vancouver, 2004.

[21] Garfield, E. The meaning of the Impact Factor. International Journal of Clinical and Health Psychology 3, 2 (2003), 363-369.

[22] Giglia, E. Academic social networks: it's time to change the way we do research. European journal of physical and rehabilitation medicine 47, 2 (2011), 345-50.

[23] Glänzel, W. and Schubert, A. Analysing Scientific Networks Through Co-Authorship. In H.F. Moed, W. Glänzel and U. Schmoch, eds., Handbook of Quantitative Science and Technology Research. Springer Netherlands, Dordrecht, 2004, 257-276.

[24] Gruzd, A. and Goertzen, M. Wired Academia: Why Social Science Scholars are using Social Media. 2013 46th Hawaii Conference on System Sciences, (2013), 3332-3341.

[25] Hanneman, R.A. and Riddle, M. Concepts and Measures for Basic Network Analysis. In J. Scott and P.J. Carrington, eds., The SAGE Handbook of Social Network Analysis. Sage, Thousand Oaks, CA, 2011, 340-369.

[26] Harzing, A.-W. Publish or Perish. 2007.

[27] Hirsch, J.E. An index to quantify an individual's scientific research output. Proceedings of the National Academy of Sciences of the United States of America 102, 46 (2005), 16569-16572.

[28] Hirsch, J.E. Does the h-index have predictive power? Proceedings of the National Academy of Sciences of the United States of America 104, 49 (2007), 19193-19198.

[29] Hughes, D.J., Rowe, M., Batey, M., and Lee, A. A tale of two sites: Twitter vs. Facebook and the personality predictors of social media usage. Computers in Human Behavior 28, 2 (2012), 561-569. 
[30] Koku, E., Nazer, N., and Wellman, B. Netting Scholars: Online and Offline. American Behavioral Scientist 43, (2000), 1-19.

[31] Kousha, K., Thelwall, M., and Rezaie, S. Using the Web for research evaluation: The Integrated Online Impact indicator. Journal of Informetrics 4, 1 (2010), 124-135.

[32] Moody, J. The Structure of a Social Science Collaboration Network: Disciplinary Cohesion from 1963 to 1999. American Sociological Review 69, 2 (2004), 213-238.

[33] Mounce, R. Open Access and Altmetrics: Distinct but Complementary. Bulletin of the American Society for Information Science and Technology 39, 4 (2013), 14-17.

[34] Nentwich, M. and König, R. Cyberscience 2.0 Research in the Age of Digital Social Networks. Campus, Frankfurt/New York, 2012.

[35] Nielsen, M. Reinventing Discovery: The New Age of Networked Science. Princeton University Press, Princeton, 2011.

[36] Pénard, T. and Poussing, N. Internet Use and Social Capital: The Strength of Virtual Ties. Journal of Economic Issues 44, 3 (2010), 569-595.

[37] PLoS Editors, T. The Impact Factor Game. PLoS Medicine 3, 6 (2006), e291.

[38] Priem, J. and Costello, K.L. How and why scholars cite on Twitter. Proceedings of the 73rd ASIST Annual Meeting 47, 1 (2010), 1-4.

[39] Priem, J. and Hemminger, B.M. Scientometrics 2.0: New metrics of scholarly impact on the social Web. First Monday 15, 7 (2010).

[40] Priem, J., Taraborelli, D., Groth, P., and Neylon, C. Altmetrics: a manifesto. October, 2010, 1-5. http://altmetrics.org/manifesto/.

[41] Priem, J. Scholarship: Beyond the paper. Nature 495, (2013), 437-440.

[42] Procter, R., Williams, R., Stewart, J., et al. Adoption and use of Web 2.0 in scholarly communications. Philosophical transactions. Series A, Mathematical, physical, and engineering sciences 368, 1926 (2010), 4039-4056.

[43] Quan-Haase, A. and Young, A.L. Uses and Gratifications of Social Media: A Comparison of Facebook and Instant Messaging. Bulletin of Science Technology Society 30, 5 (2010), 350-361.
[44] Scott, J. and Carrington, P.J. The SAGE Handbook of Social Network Analysis. SAGE, Thousand Oaks, CA, 2011.

[45] Seglen, P.O. Why the impact factor of journals should not be used for evaluating research. BMJ British Medical Journal 314, 7079 (1997), 498-502.

[46] Shema, H., Bar-Ilan, J., and Thelwall, M. Research blogs and the discussion of scholarly information. PloS one 7, 5 (2012), e35869.

[47] Thelwall, M. Journal impact evaluation: A webometric perspective. Scientometrics 92, 2 (2012), 429-441.

[48] Valenzuela, S., Park, N., and Kee, K.F. Is There Social Capital in a Social Network Site?: Facebook Use and College Students' Life Satisfaction, Trust, and Participation. Journal of Computer-Mediated Communication 14, 4 (2009), 875901.

[49] Vaughan, L. and Hysen, K. Relationship between links to journal Web sites and impact factors. Aslib Proceedings 54, 6 (2002), 356-361.

[50] Vaughan, L. and Shaw, D. Bibliographic and Web citations: What is the difference? Journal of the American Society for Information Science and Technology 54, 14 (2003), 1313-1322.

[51] Wasserman, S. and Faust, K. Social Network Analysis: Methods and Applications. Cambridge University Press, Cambridge, 1994.

[52] Watts, D.J. and Strogatz, S.H. Collective dynamics of 'small-world' networks. Nature 393, 6684 (1998), 440-2.

[53] Wellman, B., Quan-Haase, A., Witte, J., and Hampton, K. Does the Internet Increase, Decrease, or Supplement Social Capital?: Social Networks, Participation, and Community Commitment. American Behavioral Scientist 45 , 3 (2001), 436-455.

[54] White, H.C. Scientific and Scholarly Networks. In J. Scott and P.J. Carrington, eds., The SAGE Handbook of Social Network Analysis. Sage, Thousand Oaks, CA, 2011, 271-285.

[55] White, H.D., Wellman, B., and Ms, C. Does Citation Reflect Social Structure? Longitudinal Evidence from the 'Globenet' Interdisciplinary Research Group. Journal of the American Society for Information Science 55, 2 (2004), 111126. 